\title{
Dyslipidaemia of Obesity, Metabolic Syndrome and Type 2 Diabetes Mellitus: the Case for Residual Risk Reduction After Statin Treatment
}

\author{
Vasilios G. Athyros ${ }^{1, *}$, Konstantinos Tziomalos ${ }^{2}$, Asterios Karagiannis ${ }^{1}$ and Dimitri P. Mikhailidis ${ }^{2}$ \\ ${ }^{I}$ Second Propedeutic Department of Internal Medicine, Aristotle University, Hippocration Hospital, Thessaloniki, Greece \\ ${ }^{2}$ Department of Clinical Biochemistry (Vascular Prevention Clinic) and Department of Surgery, Royal Free Hospital \\ Campus, University College Medical School, University College London (UCL), London, UK
}

\begin{abstract}
Dyslipidaemia is frequently present in obesity, metabolic syndrome (MetS) and type 2 diabetes mellitus (T2DM). The predominant features of dyslipidaemia in these disorders include increased flux of free fatty acids (FFA), raised triglyceride (TG) and low high density lipoprotein cholesterol (HDL-C) levels, a predominance of small, dense (atherogenic) low density lipoprotein cholesterol (LDL) particles and raised apolipoprotein (apo) B values Posprandial hyperlipidaemia may also be present. Insulin resistance (IR) appears to play an important role in the pathogenesis of dyslipidaemia in obesity, MetS and T2DM. The cornerstone of treatment of this IR-related dyslipidaemia is lifestyle changes and in diabetic patients, tight glycaemic control. In addition to these measures, recent clinical trials showed benefit with statin treatment. Nevertheless, a substantial percentage of patients treated with statins still experience vascular events. This residual vascular risk needs to be addressed. This review summarizes the effects of hypolipidaemic drug combinations (including statins with cholesterol ester protein inhibitors, niacin, fibrates or fish oil, as well as fibrate-ezetimibe combination) on the residual vascular risk in patients with obesity, MetS or T2DM.
\end{abstract}

Keywords: Dyslipidaemia, obesity, metabolic syndrome, type 2 diabetes mellitus, residual vascular risk.

\section{INTRODUCTION}

Dyslipidaemia is an important modifiable vascular risk factor $[1,2]$. Elevated low density lipoprotein cholesterol (LDL-C) levels are the major target in the management of dyslipidaemia and statins are the most widely used hypolipidaemic agents for cardiovascular disease (CVD) prevention. However, the gains from CVD prevention over the last 4 decades are being challenged by a global epidemic of obesity, metabolic syndrome (MetS) and type 2 diabetes mellitus (T2DM) [3]. Recent epidemiological data from the USA [4] and UK [5] show an unfavourable trend in CVD mortality in younger men and women (35 to 44 years), related to the obesity, MetS and T2DM epidemic. In these age groups, CVD mortality increased significantly for the first time in over 2 decades [4, 5]. Visceral adiposity, a marker of "dysfunctional adipose tissue", plays a key role in the development of the MetS and T2DM. It is characterised by accumulation of fat in the central part of the body and correlates with insulin resistance (IR) [6]. Visceral adipocytes are large, insulin-resistant and highly active metabolically. Through the production of a variety of adipokines, adipocytes play a role in the pathogenesis of inflammation, dyslipidaemia and hypertension [7]. The co-existence of these risk factors increases the CVD morbidity and mortality

*Address correspondence to this author at the Atherosclerosis and Metabolic Syndrome Units, Second Propedeutic Department of Internal Medicine, Aristotle University, Hippocration Hospital, Thessaloniki, 55 132, Greece; Tel: +30 2310454 237; Fax: +30 2310445 220;

E-mail: athyros@med.auth.gr associated with obesity, MetS and T2DM [8]. In these disorders, the phenotype of dyslipidaemia is highly atherogenic. It usually manifests as the so-called "atherogenic lipid triad" consisting of elevated serum triglyceride (TG) levels, increased levels of small-dense LDL (sdLDL) particles and decreased levels of high density lipoprotein cholesterol (HDL-C) $[9,10]$.

We review the pathophysiology and treatment of dyslipidaemia associated with obesity, MetS and T2DM, focusing on strategies aiming at reducing the residual CVD risk [11] after statin treatment to LDL-C goal.

\section{PATHOPHYSIOLOGY OF DYSLIPIDAEMIA ASSO- CIATED WITH OBESITY, METS AND T2DM}

Patients with obesity, MetS or T2DM show specific lipid abnormalities that promote atherosclerosis and contribute to the residual CVD risk observed in these patients after LDL$\mathrm{C}$ reduction to treatment goals with statins and optimum treatment of comorbidities [11-14].

\section{A. The Atherogenic Lipid Triad}

In most cases, dyslipidaemia in patients with obesity, MetS and T2DM is characterized by (a) increased flux of free fatty acids (FFA), (b) raised TG values, (c) low HDL-C values, (d) increased small, dense LDL particles, and (e) raised apolipoprotein (apo) B levels $[15,16]$.

IR appears to play an important role in the pathogenesis of this type of dyslipidaemia [17]. IR is associated with enhanced lipolysis as well as reduced FFA uptake and esterifi- 
cation leading to an increased flux of FFA into non-adipose tissues, including the liver and muscle [17, 18]. Since FFA compete with glucose for cellular uptake and metabolism, they can further reduce insulin sensitivity, instituting a vicious cycle $[19,20]$.

Adipose tissue, through the secretion of adipokines [7], plays a central role in whole body homeostasis including food intake, regulation of energy balance, insulin action, lipid and glucose metabolism, angiogenesis and vascular remodelling, regulation of blood pressure (BP) and coagulation [21]. Excessive visceral adiposity increases the availability of FFA through the hydrolysis of adipocyte TG by a variety of lipases, including triglyceride lipase, lipoprotein lipase (LpL), hormone-sensitive lipase and endothelial lipase $[22,23]$. Such increases in circulating FFA lead to TG accumulation in muscle and liver (fatty liver) and raise circulating TG levels due to enhanced hepatic production of very low density lipoprotein (VLDL) cholesterol [22, 24]. Excess VLDL secretion increases the flux of FFA and TG to muscle and other tissues, further inducing IR. When influx of FFA to the liver exceeds efflux, there is increased hepatic FFA uptake, synthesis and secretion that can lead to hepatic steatosis, which in turn exacerbates IR [25, 26], giving rise to a new vicious cycle. In addition, overloading of the white adipose tissue (WAT) beyond its storage capacity can also adversely affect skeletal and cardiac muscle, liver as well as pancreatic function [27].

Cholesteryl ester transfer protein (CETP) is secreted by the adipose tissue and is an important determinant of lipoprotein composition because it mediates the transfer of cholesteryl esters (CE) from CE-rich lipoproteins to TG-rich lipoproteins in exchange for TG [28]. In obese patients, CETP activity and mass are increased [29]. This contributes to the increased flux of FFA but also to the rise in circulating TG levels. However, increased flux of FFA from the periphery to the liver in IR states stimulates hepatic TG synthesis, which in turn promotes the production of VLDL and apoB $[16,29]$. Several studies showed that hepatic apoB secretion is metabolically regulated [15]. The apoB gene is constitutively expressed and in most cases the modulation of apoB production does not involve changes in apoB mRNA levels [15]. These observations suggest that post-translational mechanisms play a role in the regulation of apoB levels, including endoplasmic reticulum translocation and protein degradation. Thus, reduced apoB degradation might be the main contributor to the increase in plasma apoB levels [17, 30]. On the other hand, hepatic IR can lead to increased availability of apoB and might predispose to higher rates of hepatic VLDL assembly and secretion, the key steps in the development of metabolic dyslipidaemia [25]. In lean subjects, all these factors would stimulate adiponectin production from the WAT $[7,21]$. Adiponectin reduces hepatic TG production and increases insulin sensitivity [7, 31]. However, this compensatory mechanism is blunted in obesity, because adiponectin levels are low and do not increase under physiological stimuli $[7,21]$.

In IR, circulating HDL-C levels are also decreased and this appears to be linked to the overproduction of TG-rich lipoproteins. Low HDL-C levels represent an independent risk factor for CVD [32-34]. Even though the mechanisms are not entirely clear, the enrichment of HDL particles with
TG appears to be implicated, leading to HDL particle instability and degradation. CETP plays an important role in lipid exchange between TG-rich lipoproteins and HDL [35, 36]. In the presence of raised plasma TG levels, CETP mediates the exchange of TG (from VLDL) for CEs (from HDL), resulting in HDL particles enriched in TG and depleted of CE, which are prone to degradation [37]. These TG-rich but cholesterol-depleted HDL particles undergo hydrolysis of their TG component by hepatic lipase (HL), which plays an important role in the enhanced catabolism of HDL in IR states [38]. ApoA, the main protein of HDL, is then dissociated from HDL particles [39]. Coupled with increased catabolic rate, these changes result in reduced and TG-rich HDL particles, which cannot carry out reverse cholesterol transport effectively [40]. Another possibility is that the altered (due to IR) lipid flux in the liver may reduce the hepatic production of apoA [41]. Thus, both depletion of HDL particles from $\mathrm{CE}$ by CETP and alterations in apoA might contribute to the reduction in HDL-C mass and HDL particle size (HDL-3) [37-41]. It was shown that as the number of MetS components increases, the HDL phenotype shifts to a greater percentage of small HDL-3 and less large HDL-2 particles, resulting in a decreased HDL-2/HDL-3 ratio [42]. In addition, HDL-2 levels and the HDL-2/HDL-3 ratio independently correlated with HDL-C (positively) and TG levels (negatively). HDL-3 concentration positively correlated with HDL-C and TG levels. This phenomenon may contribute to an impaired reverse cholesterol transport and to attenuated antiatherogenic activity of HDL in MetS [42].

Patients with IR have normal or slightly elevated LDL-C levels but significantly higher concentrations of the atherogenic sdLDL subfractions [43-45]. Hypertriglyceridaemia is implicated in the increased presence of sdLDL particles in IR. In hypertriglyceridaemic states, large TG-rich VLDL (VLDL1) molecules accumulate [43]. When VLDL1 is lipolysed by LpL, a population of LDL particles with changed apoB conformation is produced. These particles fail to bind efficiently to LDL receptors and have a prolonged residence time in the circulation. Through the action of CETP, CEs are replaced by TG in LDL and HDL particles [43]. HL also acts on TG-rich LDL to generate sdLDL, which is associated with higher vascular risk [46, 47]. This is because sdLDL particles have reduced LDL receptormediated clearance, increased retention in the arterial wall, increased susceptibility to oxidation and are enriched in apoB $[44,48]$. It was shown that higher apoB levels predict CVD better than the absolute LDL-C levels [49] and are the most prevalent lipid disorder in patients with premature coronary artery disease (CAD) [50]. Interestingly, both sdLDL and the sdLDL-C/LDL-C ratio are inversely related with adiponectin levels [51]. Thus, hypoadiponectinaemia may provide a useful index for qualitative changes in LDL particles in IR states, especially when combined with the measurement of apoB levels [15].

\section{B. Postprandial Lipaemia}

Postprandial lipaemia refers to the state of lipid metabolism between food intake and the post-absorptive state. Fasting hypertriglyceridaemia is an independent risk factor for CVD [52, 53]. Moreover, TG levels are predictive of subsequent CVD events in statin-untreated high-risk patients and the statin-induced reduction in TG levels is associated with 
lower vascular risk [54]. This beneficial effect of statins was more pronounced in patients with MetS or T2DM [54]. On the other hand, postprandial hyperlipidaemia (mainly postprandial hypertriglyceridaemia) is frequently present in patients with premature CVD [55]. It was suggested that fasting plasma TG concentrations are the best predictor of postprandial lipaemia $[56,57]$. However, postprandial lipaemia occurs even in subjects who are normolipidaemic in the fasting state $[58,59]$.

Since postprandial hyperlipidaemia is relatively common in IR states $[60,61]$, it is probable that the clearance of both chylomicrons and VLDL from the circulation is impaired in these patients. In IR, the antilipolytic effect of insulin in adipose tissue is attenuated [62]. This might contribute to the postprandial increase in FFA levels [15]. The mechanisms underlying postprandial hyperlipidaemia also include a modest reduction in $\mathrm{LpL}$ and $\mathrm{HL}$ activity, increased production and higher plasma levels of apoC-III (an inhibitor of LpL) and the defective suppression of hepatic VLDL secretion postprandially [63-65]. Because VLDL and chylomicrons compete for the same LpL- and receptor-mediated TGremoving pathways, nonsuppressed VLDL secretion reduces the clearance of chylomicrons and their remnants. Postprandial hyperlipidaemia also promotes the formation of atherogenic LDL and HDL particles in a way similar to fasting hypertriglyceridaemia, as described above [60].

\section{TREATMENT}

\section{A. Weight Loss}

Obesity is an important vascular risk factor [1, 66]. Weight loss with lifestyle measures (diet and exercise) remains the first priority in IR patients in order to control dyslipidaemia and prevent T2DM, but is difficult to achieve and maintain $[67,68]$. Therefore, drugs that facilitate weight loss might prove useful. Modest weight loss (>5\%) with either sibutramine or orlistat appears to be associated with a reduction in TG levels and with favourable changes in adipokines, including an increase in serum adiponectin and a decrease in serum resistin levels $[69,70]$. In obese T2DM patients with MetS, orlistat plus diet improved several vascular risk factors including fasting glucose, $\mathrm{HbA1c}$, total cholesterol and LDL-C levels, systolic BP, waist circumference and homeostasis model assessment index (HOMA) compared with diet and exercise alone [71]. Similar were the findings in the XENical in the prevention of Diabetes in Obese Subjects (XENDOS) Trial [72] in obese subjects without T2DM, in patients with T2DM on oral hypoglycaemic drugs [73] and in patients with T2DM on insulin [74]. Thus, the combination of weight loss with the beneficial effects on adipokine levels during orlistat treatment might provide additional clinical benefits in obese patients with T2DM.

Young morbidly obese patients (body mass index (BMI) $>40 \mathrm{~kg} / \mathrm{m}^{2}$ or BMI $>35 \mathrm{~kg} / \mathrm{m}^{2}$ in the presence of significant comorbidities) have an estimated $22 \%$ reduction in expected remaining lifespan, representing an approximate loss of 12 years of life [75]. In these patients, bariatric surgery is an effective treatment [76]. Bariatric surgery results in significant weight loss (approximately 50-70\% of excessive body weight), has a $70 \%$ long-term success rate and improves associated comorbidities (hypertension, dyslipidaemia, T2DM and obstructive sleep apnea) [77-79]. The beneficial effects of bariatric surgery on adipokine levels might play a role in the observed weight loss [80-82].

\section{B. Drug Treatment}

\section{Statin Treatment}

As mentioned above, IR-associated dyslipidaemia is characterized by elevated TG and low HDL-C levels and a preponderance of sdLDL particles, while LDL-C levels are similar to subjects without IR. The cornerstone of treatment for IR-related dyslipidaemia is lifestyle changes and in diabetic patients, tight glycaemic control. In addition to these measures, recent clinical trials demonstrated the benefits of statin treatment [83]. In the Collaborative Atorvastatin Diabetes Study (CARDS), atorvastatin (10 mg/day) reduced vascular events, including stroke, in patients with T2DM without high LDL-C [3.1 mmol/1 $(120 \mathrm{mg} / \mathrm{dl})]$ and without CVD at baseline [84]. In post hoc analyses of the GREek Atorvastatin and Coronary heart disease Evaluation (GREACE) study, we showed that patients with CAD and MetS [85] or T2DM [86] benefit from statin treatment more than those without MetS or T2DM. Statin treatment (mainly atorvastatin) substantially reduced total mortality and CVD events by nearly one-half compared with untreated patients within a 3-year follow-up period. The Heart Protection Study (HPS) [87] showed a reduction in CVD events in patients with T2DM with or without CVD with simvastatin (40 mg/day). The Treating to New Targets (TNT) study also showed that patients with CAD and MetS [88] or T2DM [89] are at higher risk compared with patients without MetS or T2DM. Moreover, these 2 prespecified analyses of the TNT study showed that patients with CAD and MetS or T2DM benefit from aggressive LDL-C lowering with atorvastatin more than CAD patients without MetS of T2DM [88, 89]. Furthermore, a recent meta-analysis of 14 randomized statin trials including 18, 686 patients with T2DM showed a $21 \%$ reduction in major vascular events and $13 \%$ reduction in vascular mortality for every $1 \mathrm{mmol} / \mathrm{l}(37 \mathrm{mg} / \mathrm{dl})$ reduction in LDL-C levels [90]. In the Justification for the Use of Statins in Prevention: an Intervention Trial Evaluating Rosuvastatin (JUPITER) trial, 7, 375 participants (41.4\% of the study population) had MetS without T2DM [91]. Patients enrolled in the JUPITER trial had LDL-C levels < $130 \mathrm{mg} / \mathrm{dl}(3.4$ $\mathrm{mmol} / \mathrm{l}$ ) and no T2DM or established vascular disease but had elevated high sensitivity C-reactive protein (hsCRP) levels ( $\geq 2 \mathrm{mg} / \mathrm{l})$ [91]. Those treated with $20 \mathrm{mg}$ of rosuvastatin had significant reductions in vascular morbidity and mortality and in total mortality after a median follow-up of 1.9 years [91]. In JUPITER, rosuvastatin significantly reduced the risk for the primary end-point (myocardial infarction, stroke, arterial revascularization, hospitalization for unstable angina, vascular death) in both patients with and without MetS, with no evidence of heterogeneity between these subgroups ( $p$ for interaction $=0.14$ ) [91]. JUPITER is the first study that showed a reduction in vascular events with statin treatment in patients with MetS but without established vascular disease or T2DM [91].

Nevertheless, even after the statin-induced reductions in CVD morbidity and mortality in the above studies it is obvious that a substantial percentage of patients still have a vascular event. Thus, it seems that there is a residual CVD risk 
that needs to be targeted [92]. Therefore, it might be useful to combine statins with other lipid-lowering agents to manage residual CVD risk. These agents might include a fibrate, niacin, fish oil or (possibly in the future) CETP inhibitors [93]. This is supported by the findings of an analysis of the Get With The Guidelines database (136, 905 patients hospitalized with CAD from 2000 to 2006). Almost half of the patients had admission LDL-C levels < $2.6 \mathrm{mmol} / \mathrm{l}(100$ $\mathrm{mg} / \mathrm{dl}$ ) but more than half had admission HDL-C levels $<1.0$ $\mathrm{mmol} / \mathrm{l}(40 \mathrm{mg} / \mathrm{dl})$. Less than $10 \%$ had HDL-C levels $\geq 1.5$ $\mathrm{mmol} / \mathrm{l}(60 \mathrm{mg} / \mathrm{dl})$ [94]. These findings suggest that target LDL-C goals should be lower and that effective treatments to raise HDL-C should be used or developed [95]. In A Study to Evaluate the Effect of Rosuvastatin on Intravascular Ultrasound-Derived Coronary Atheroma Burden [ASTEROID]), rosuvastatin $40 \mathrm{mg} /$ day achieved an average LDL-C concentration of $1.6 \mathrm{mmol} / \mathrm{l}(60.8 \mathrm{mg} / \mathrm{dl})$ and increased HDL-C by $14.7 \%$, resulting in significant regression of coronary atherosclerosis assessed with intravascular ultrasound (IVUS) [96]. A meta-analysis of IVUS trials showed that statin treatment is associated with regression of coronary atherosclerosis when LDL-C levels are substantially reduced and HDL-C levels are increased by more than 7.5\% [97]. These findings suggest that statin benefits result from both the reduction in LDL-C levels and the increase in HDL-C. In the GREACE study, the statin-induced HDL-C increase was independently associated with lower CVD event rates [32, 98]. This suggests that the vascular risk reduction associated with HDL-C rise is significant even during aggressive LDLC-lowering treatment ( $46 \%$ mean reduction in LDL-C levels) [32, 98]. Interestingly, rosuvastatin increased HDL-C levels by increasing the cholesterol mass only in the larger HDL particles in a dose-dependent manner, suggesting a more effective reverse cholesterol transport [99]. Atorvastatin also reduced all LDL subclasses, resulting in a significant reduction in LDL particle number and in an increase in LDL particle size [100]. In addition, HDL particle size increased [100]. Statins also have beneficial effects on postprandial lipaemia [101].

Statin-induced HDL-C increase is also related to a significant improvement in renal function [102]. High-risk patients with dyslipidaemia show a decline in renal function over time, which further increases the risk for vascular events [85, 103-106]. Statin treatment improved renal function and the statin-induced HDL-C increase appears to contribute to this effect [106]. Improved reverse cholesterol transport or other "pleiotropic" actions of HDL particles might play a role in the beneficial effects of HDL-C on renal function [102]. In addition, this improvement in renal function is independently associated with a reduction in vascular events [85, 103-106]. These finding support the concept that improving lipid variables other than LDL-C also benefit renal function.

\section{Statin Combined with Novel Agents for Raising HDL-C}

After attaining the LDL-C goals, the most promising lipid risk factor to target seems to be HDL-C. The effects of statins on HDL-C levels depend on the compound, dose and lipid phenotype [107]. Statins do not appear to be the most appropriate hypolipidaemic agents to increase HDL-C levels [96]. In this respect, novel agents (which might be available in the near future) including apo-I (Milano), anti CETP vac- cine (CETi-1) and CETP inhibitors (anacetrapib or JTT705), might prove to be useful. The most promising regimen appears to be CETP inhibition combined with a statin [95, 108]. A recent publication suggests that anacetrapib (which is well tolerated and had no effect on BP), as monotherapy or co-administered with atorvastatin, significantly lowered LDL-C and increased HDL-C levels [108]. The net result of treatment with anacetrapib + atorvastatin was $\approx 70 \%$ lowering of LDL-C and more than doubling of HDL-C levels [108]. In contrast, torcetrapib (a CETP inhibitor whose development was halted because of increased mortality) raised BP independently of CETP inhibition [109, 110]. An increase in circulating aldosterone levels appears to contribute to this BP rise with torcetrapib [110]. It appears that this adverse action is not a drug class effect but compound-specific. Anacetrapib was associated with a dose-dependent lipoprotein a $[\mathrm{Lp}(\mathrm{a})]$ lowering, with up to $50 \%$ reduction at the highest doses [108]. It remains to be established whether these effects of anacetrapib on lipid parameters will translate into clinical benefit.

\section{Statin-Niacin Combination Treatment}

In the HDL-Atherosclerosis Treatment Study (HATS) [111] and the Arterial Biology for the Investigation of the Treatment Effects of Reducing Cholesterol 3 (ARBITER 3) study [112], niacin-statin combination vs statin alone resulted in greater reduction in carotid intima-media thickness (cIMT) in patients with CAD, T2DM and/or MetS. Combining niacin with statins to optimize the lipid profile [lower TG levels below $1.7 \mathrm{mmol} / \mathrm{l}$ (150 levels $\mathrm{mg} / \mathrm{dl})$ and non-HDL-C levels below $3.4 \mathrm{mmol} / \mathrm{l}(130 \mathrm{mg} / \mathrm{dl})$ ] might be useful in T2DM. However, higher doses of niacin can impair glycaemic control [67]. Therefore, niacin therapy should be instituted only in patients with well-controlled diabetes and glucose levels should be monitored. In patients with T2DM but without CAD, it is recommended to achieve LDL-C levels below $2.6 \mathrm{mmol} / \mathrm{l}(100 \mathrm{mg} / \mathrm{dl})$ whereas in patients with T2DM and CAD the goal is to achieve LDL-C levels below $1.8 \mathrm{mmol} / 1(70 \mathrm{mg} / \mathrm{dl})$ [113]. In both groups, non-HDL-C levels should be $<3.4 \mathrm{mmol} / \mathrm{l}(130 \mathrm{mg} / \mathrm{dl})$ and $<2.6 \mathrm{mmol} / 1$ (100 mg/dl), respectively [113]. In diabetic patients, it is also desirable to achieve TG levels $<1.7 \mathrm{mmol} / \mathrm{l}(150 \mathrm{mg} / \mathrm{dl})$ and HDL-C levels $>1.0 \mathrm{mmol} / \mathrm{l}(40 \mathrm{mg} / \mathrm{dl})$ and $>1.3 \mathrm{mmol} / \mathrm{l}(50$ $\mathrm{mg} / \mathrm{dl}$ ) in men and women, respectively [114]. Niacin-statin combination therapy could possibly help achieve these additional goals; however, there is no clear evidence that this combination will reduce vascular events more than statins alone in diabetic patients [67].

\section{Statin-Fibrate Combination Treatment}

Mounting evidence suggests that TG play a role in the pathogenesis of atherothrombosis [115]. Recent post hoc analyses of statin trials suggest that lowering TG levels is associated with a reduction in vascular events [54, 116]. Statin-induced TG lowering may translate in clinical benefit both in patients with acute coronary syndromes and stable CAD, beyond LDL-C lowering to $<1.8 \mathrm{mmol} / \mathrm{l}(70 \mathrm{mg} / \mathrm{dl})$ or $<2.6 \mathrm{mmol} / \mathrm{l}(100 \mathrm{mg} / \mathrm{dl})$, respectively $[54,116]$.

The main effect of fibrates is a decrease in TG levels (by about 20-30\% in major outcomes studies [117-121], although larger reductions may be seen in patients with above average pre-treatment TG levels) $[122,123]$. There is also a 
reduction in postprandial TG levels and remnant lipoprotein particles, especially in patients with T2DM or MetS [122, 123-126]. Fibrates also raise HDL-C (by 5-10\%) by stimulating apoA-I and apoA-II expression [123, 127]. Fenofibrate also lowers LDL-C, more so in patients with average than in those with high baseline TG levels [117, 128]. A study using nuclear magnetic resonance (NMR) analysis showed that fenofibrate lowered TG levels by $58 \%$ and increased HDL-C levels by $18 \%$ [129]. NMR analysis revealed that VLDL, particularly large VLDL, intermediate density lipoprotein (IDL) and sdLDL were also significantly decreased and LDL distribution was shifted towards larger particles. HDL distribution was also altered; there was an increase in small HDL and a decrease in large HDL particles, resulting in a significant decrease in HDL particle size, from 9.1 to $8.9 \mathrm{~nm}$, as well as a $27 \%$ increase in HDL particle number. Among inflammation markers, hsCRP was significantly decreased by $42 \%$ [129]. Moreover, fenofibrate also lowers apoCIII levels [130-132] and exerts anti-inflammatory actions [123, 129, 133].

The Fenofibrate Intervention and Even Lowering in Diabetes (FIELD) study evaluated the effect of treatment with fenofibrate $200 \mathrm{mg} /$ day in reducing macrovascular and microvascular complications in 9, 795 patients with T2DM [134]. At the end of the 5-year follow-up period, treatment with fenofibrate was associated with a nonsignificant $11 \%$ reduction in relative risk for the primary end point. There was, however, a significant $11 \%$ relative reduction in risk for the secondary end point of total cardiovascular events, excluding unstable angina, and this was largely driven by significant reduction in risk for nonfatal MI and coronary and all revascularization procedures. Regarding the microvascular complications of T2DM, fenofibrate significantly decreased the need for retinal laser therapy by $30 \%$ and reduced the progression of albuminuria [134]. Therefore, combining statins with fenofibrate might further reduce vascular risk in IR states [135]. However, it should be emphasized there is limited evidence to support this recommendation.

Long-term statin-fibrate combination in patients with familial combined hyperlipidaemia (FCHL) resulted in more effective control of multiple lipid parameters including LDLC, TG and HDL-C as well as plasma fibrinogen levels, than either monotherapy alone, with a similar safety profile [136138]. Moreover, statin-fibrate combination increased LDL particle size in patients with FCHL [139]. However, statinfibrate combinations are not widely used. This might be due to safety concerns, particularly for myopathy and rhabdomyolysis, which was reported with lovastatin-gemfibrozil combination [140]. However, this increased risk for rhabdomyolysis was not confirmed in studies with other statin-fibrate combinations [136-139, 141, 142]. Uncontrolled studies suggested that statin-fibrate combination reduces total and CAD mortality in patients with FCHL [143]. The combined targeting of LDL-C, TG, apoB and fibrinogen, as well as the increase in LDL particle size, HDL-C and apoA-I might play a role in these beneficial effects of statin-fibrate combination.

The features of dyslipidaemia of IR states are similar to those of FCHL [144]. Moreover, metabolic abnormalities, such as the predominance of sdLDL particles and increased glycation of LDL [145], raise the vascular risk in these pa- tients. Glycaemic control appears to improve but does not normalize these abnormalities [146]. Statin or fibrate monotherapy can improve the lipid profile in patients with T2DM; however, they affect different aspects of lipoprotein metabolism [147-149]. Hence, it is difficult to normalize all lipid abnormalities in patients with T2DM using monotherapy with either a statin or a fibrate [114]. In contrast, atorvastatin-fenofibrate combination improved multiple lipid and coagulation abnormalities and reduced the estimated CAD risk by $80 \%$ in patients with T2DM [148]. Therefore, combining statins with fibrates appears to expand the spectrum of therapeutic choices and allow the individualization of hypolipidaemic treatment in patients with IR.

Non-alcoholic fatty liver disease (NAFLD) is a common condition (with a prevalence of $10-39 \%$ in the general population) characterized by significant lipid deposition in the hepatocytes in patients without a history of excessive alcohol ingestion [150]. It was shown that IR is associated with NAFLD [151]. It was suggested that NAFLD might represent another feature of MetS [152] with decreased insulin sensitivity being the common underlying factor [153]. The strong association of NAFLD with other features of the MetS including obesity, central fat distribution, T2DM, dyslipidaemia, hypertension and CVD, further supports this hypothesis [154, 155]. Both MetS and NAFLD appear to be independent vascular risk factors [156]. A multifactorial approach reversed both MetS and NAFLD and reduced estimated CAD risk [157, 158]. Atorvastatin-fenofibrate combination was more effective than either monotherapy [157, 158].

\section{Statin-Omega 3 Combination Treatment}

Omega-3 fatty acids [n-3 polyunsaturated fatty acids (PUFA)], including the 20-carbon eicosapentaenoic acid (EPA) and the 22-carbon docosahexaenoic acid (DHA), lower TG levels and atherogenic remnant lipoproteins both in patients with or without T2DM [159-161]. In the former, n-3 PUFA might raise LDL-C levels but do not affect glycaemic control [160].

Until recently, there were only a few data regarding the efficacy of n-3 PUFA supplementation in the primary prevention of CVD. Thus, the results of the Japan EPA Lipid Intervention Study (JELIS) offer a new insight in the role of n-3 PUFA in this setting. In this study, 18, 645 hypercholesterolaemic patients were randomly assigned to receive either $1,800 \mathrm{mg}$ of EPA daily with statin (EPA group; $\mathrm{n}=9,326$ ) or statin only (controls; $n=9,319)$ [162]. The primary endpoint was any major coronary event, including sudden cardiac death, fatal and non-fatal MI, and other non-fatal events including unstable angina pectoris, angioplasty, stenting or coronary artery bypass grafting (CABG) [162]. After a mean follow-up of 4.6 years, a $19 \%$ relative reduction in the primary endpoint was detected in the EPA group $(2.8 \%$ in the EPA group vs $3.5 \%$ in the control group; $p=0.011$ ) [162]. Even though the JELIS trial was underpowered for analysis of subgroups, EPA treatment resulted in a significant $19 \%$ reduction in major coronary events among patients with a history of CAD (secondary prevention subgroup; $n=3,664$ ); the primary end-point occurred in $8.7 \%$ in the EPA group vs $10.7 \%$ in the control group $(p=0.048)$ [162]. In patients without CAD (primary prevention subgroup; $n=14,981$ ), 
EPA treatment reduced major coronary events by $18 \%$, but this was not significant $(1.4 \%$ in the EPA group vs $1.7 \%$ in the control group; $p=0.132$ ) [162]. The relationship between incident CAD, the number of CAD risk factors and EPA treatment was also investigated [163]. Compared with patients with normal serum TG and HDL-C levels, those with abnormal levels had significantly higher CAD hazard ratio (HR) $(1.71 ; 95 \%$ confidence interval (CI): 1.11-2.64; $p$ $=0.014)$. In this higher risk group, EPA treatment reduced CAD risk by $53 \%$ (HR: 0.47 ; 95\% CI: $0.23-0.98$; $\mathrm{p}=0.043$ ) [163]. Therefore, the beneficial effects of EPA on top of statin treatment were similar in magnitude in both the primary prevention and the secondary prevention subgroups, but were significant only in the latter subgroup probably because of a greater number of events [162]

It is of interest that, in the JELIS study, the reduced risk associated with EPA treatment was confined to non-fatal coronary events [162]. No effect of EPA was observed in terms of coronary death or sudden cardiac death [162]. These findings differ from those in most previous observational studies, where fish intake primarily reduced the risk of fatal coronary events or sudden cardiac deaths, but not of nonfatal coronary events [164-166]. It has been speculated that the absence of significant effect on cardiac death in JELIS might be due to the increased consumption of fish among Japanese, which is approximately $900 \mathrm{mg}$ EPA+DHA per day [167]. A recent study also showed that EPA supplementation (1.8 g/day) reduced the progression of cIMT in patients with T2DM [168]. Thus, it has been suggested that the main benefit at lower levels of consumption (e.g. $1 \mathrm{~g} /$ day of EPA+DHA) might be prevention of ventricular arrhythmia and sudden cardiac death [169], whereas at high levels of consumption (e.g. 2-4 g/day of EPA+DHA), modest benefits for non-fatal coronary events could also begin to occur because of the other cardioprotective effects of n-3 PUFA [170]. The above suggest that when considering adding a second agent to statins in patients with combined dyslipidaemia, omega-3 fatty acids provide additional lipid improvements without increasing the risk for adverse muscle or liver effects [171].

\section{Statin-Ezetimibe Combination Treatment}

In patients who cannot reach LDL-C target with statin monotherapy, adding ezetimibe is a therapeutic option [172]. When added to a statin, ezetimibe lowered LDL-C levels by approximately $23 \%[173,174]$. Besides its LDL-C lowering action, ezetimibe may reduce the percentage of sdLDL particles in patients with high TG levels $[175,176]$. In a metaanalysis of 5, 039 patients, ezetimibe significantly increased HDL-C levels and lowered TG levels [174]. Ezetimibe also exerts anti-inflammatory effects and a recent meta-analysis reported an additional 10\% reduction in hsCRP levels when this agent was added to statins [173, 177]. Ezetimibe also appears to improve renal function [178-180]. In patients with T2DM or MetS, statin-ezetimibe combination lowered LDLC, TG, non-HDL-C and hsCRP levels and increased HDL-C levels more than statin monotherapy [181, 182]. In other studies in patients with MetS, simvastatin $80 \mathrm{mg} /$ day induced similar or greater improvements in postprandial lipaemia compared with ezetimibe plus simvastatin $10 \mathrm{mg} /$ day $[183,184]$. However, only the combination prevented fat- load-induced endothelial dysfunction [184]. Endothelial dysfunction appears to be present in patients with MetS [185].

\section{Ezetimibe-Fibrate Combination Treatment}

In dyslipidaemic patients with IR who are intolerant to statins, ezetimibe-fibrate combination is a reasonable treatment option [186]. This strategy induces changes reflecting the combined effects of fenofibrate in reducing TG-rich lipoproteins and promoting a shift in the LDL particle distribution profile toward larger, more buoyant particles and of ezetimibe in promoting reductions in cholesterol mass across the apoB particle spectrum [187]. Thus, it seams that this coadministration provides a complementary therapy that improves the atherogenic lipid profile of patients with mixed hyperlipidaemia or postprandial hyperlipidaemia [186-188].

\section{CONCLUSIONS}

In order to address the residual CVD risk and optimize the lipid profile in patients with IR (obesity, MetS and T2DM), it appears that, in addition to targeting the LDL-C (to below $2.6 \mathrm{mmol} / 1<100 \mathrm{mg} / \mathrm{dl}$ ), there is a potential benefit from raising the HDL-C level and lowering TG-rich particles [(non-HDL-C levels to below $3.4 \mathrm{mmol} / \mathrm{l}(130 \mathrm{mg} / \mathrm{dl})]$ in patients without CAD. In those with IR and CAD we have to aim at lower targets [LDL-C level $<1.8 \mathrm{mmol} / \mathrm{l}(70 \mathrm{mg} / \mathrm{dl})$ and non-HDL-C level < $2.6 \mathrm{mmol} / \mathrm{l}(100 \mathrm{mg} / \mathrm{dl})$ ] [113]. ApoB might be more predictive of CVD events than LDL-C, at least in patients with higher cardiometabolic risk [189]. Elevated apoB levels might also play a role in the increased vascular risk in patients with MetS who belong to other ethnic groups (e.g. South Asians) [190]. The effects of lifestyle modification and drug treatment on LDL particle size [191, 192], HDL particle size [99] and reverse cholesterol transport $[193,194]$ appear to play an important role in reducing residual CVD risk [195].

To address the challenge posed by the global epidemic of obesity, MetS and T2DM, we need to emphasize education and communication to increase awareness of the important contribution of IR-associated atherogenic dyslipidaemia to the residual vascular risk. Lifestyle modification is an important, effective and underutilised first step in reducing this risk. Pharmacological interventions aiming at achievement of all lipid targets is also likely to be required, with a combination of statin with other hypolipidaemic agents being the treatment of choice in most cases.

\section{DECLARATION OF INTEREST}

This review was written independently; no company or institution supported it financially. Some of the authors attended conferences, given lectures and participated in advisory boards or other trials sponsored by various pharmaceutical companies.
ABBREVIATIONS
BMI $=$ Body mass index
$\mathrm{BP}=$ Blood pressure
CAD $=$ Coronary artery disease
CETP $=$ Cholesteryl ester transfer protein 


$\begin{array}{ll}\text { CVD } & =\text { Cardiovascular disease } \\ \text { HDL-C } & =\text { High density lipoprotein cholesterol } \\ \text { HL } & =\text { Hepatic lipase } \\ \text { HOMA } & =\text { Homeostasis model assessment index } \\ \text { hsCRP } & =\text { High sensitivity C-reactive protein } \\ \text { IR } & =\text { Insulin resistance } \\ \text { LpL } & =\text { Lipoprotein lipase } \\ \text { Lp-PLA(2) } & =\text { Lipoprotein-associated phospholipase A2 } \\ \text { LDL-C } & =\text { Low density lipoprotein cholesterol } \\ \text { MetS } & =\text { Metabolic syndrome } \\ \text { PUFA } & =\text { Polyunsaturated fatty acids } \\ \text { T2DM } & =\text { Type } 2 \text { diabetes mellitus } \\ \text { VLDL-C } & =\text { Very low density lipoprotein cholesterol } \\ \text { WAT } & =\text { White adipose tissue }\end{array}$

\section{REFERENCES}

[1] Yusuf S, Hawken S, Ônpuu S, et al, on behalf of the INTERHEART Study Investigators. Effect of potentially modifiable risk factors associated with myocardial infarction in 52 countries (the INTERHEART study): Case-control study. Lancet 2004; 364: 937-52.

[2] Windler E, Choffauer M, Zyriax BC. The significance of low HDL-cholesterol levels in an ageing society at increased risk for cardiovascular disease. Diabetes Vasc Dis Res 2007; 4: 136-42.

[3] Zimmet P, Alberti KG, Shaw J. Global and societal implications of the diabetes epidemic. Nature 2001; 414: 782-7.

[4] Ford ES, Capewell S. Coronary heart disease mortality among young adults in the US from 1980 through 2002: concealed leveling of mortality rates. J Am Coll Cardiol 2007; 50: 2128-32.

[5] O'Flaherty M, Ford E, Allender S, Scarborough P, Capewell S. Coronary heart disease trends in England and Wales from 1984 to 2004; concealed levelling of mortality rates among young adults. Heart 2008; 94: 178-81.

[6] McFarlane S, Banerji M, Sowers JR. Insulin resistance and cardiovascular disease. J Clin Endocrinol Metab 2001; 86: 713-8.

[7] Athyros VG, Tziomalos K, Karagiannis A, Anagnostis P, Mikhailidis DP. Should adipokines be considered in the choice of treatment of obesity-related health problems? Curr Drug Targets 2010; 11(1): 122-35.

[8] Sowers JR. Recommendations for special populations: diabetes mellitus and the metabolic syndrome. Am J Hypertens 2003; 16: 41S-45S.

[9] Vinik AI. The metabolic basis of atherogenic dyslipidemia. Clin Cornerstone 2005; 7: 27-35.

[10] Nesto RW. Beyond low-density lipoprotein: addressing the atherogenic lipid triad in type 2 diabetes mellitus and the metabolic syndrome. Am J Cardiovasc Drugs 2005; 5: 379-87.

[11] Fruchart JC, Sacks F, Hermans MP, et al. The Residual Risk Reduction Initiative: a call to action to reduce residual vascular risk in patients with dyslipidemia. Am J Cardiol 2008; 102 (10 Suppl): $1 \mathrm{~K}-34 \mathrm{~K}$

[12] Betteridge DJ, Verges B. Long-term effects on lipids and lipoproteins of pioglitazone versus gliclazide addition to metformin and pioglitazone versus metformin addition to sulphonylurea in the treatment of type 2 diabetes. Diabetologia 2005; 48: 2477-81.

[13] Kannel WB. Lipids, diabetes, and coronary heart disease: insights from the Framingham Study. Am Heart J 1985; 110: 1100-7.

[14] Gardner CD, Fortmann SP, Krauss RM. Association of small lowdensity lipoprotein particles with the incidence of coronary artery disease in men and women. JAMA 1996; 276: 875-81.

[15] Kolovou GD, Anagnostopoulou KK, Cokkinos DV. Pathophysiology of dyslipidaemia in the metabolic syndrome. Postgrad Med J 2005; 81: 358-66.

[16] Ginsberg HN, Huang LS. The insulin resistance syndrome: impact on lipoprotein metabolism and atherothrombosis. J Cardiovasc Risk 2000; 7: 325-31.
[17] Adeli K, Taghibiglou C, Van Iderstine SC, Lewis GF. Mechanisms of hepatic very low-density lipoprotein overproduction in insulin resistance. Trends Cardiovasc Med 2001; 11: 170-6.

[18] Semenkovich CF. Fatty acid metabolism and vascular disease. Trends Cardiovasc Med 2004; 14: 72-6.

[19] Dresner A, Laurent D, Marcucci M, et al. Effects of free fatty acids on glucose transport and IRS-1-associated phosphatidylinositol 3kinase activity. J Clin Invest 1999; 103: 253-9.

[20] Shulman GI. Cellular mechanisms of insulin resistance in humans. Am J Cardiol 1999; 84: 3J-10J.

[21] Bakhai A. Adipokines-targeting a root cause of cardiometabolic risk. Q J Med 2008; 101: 767-76.

[22] Chapman MJ, Spositoc AC. Hypertension and dyslipidaemia in obesity and insulin resistance: Pathophysiology, impact on atherosclerotic disease and pharmacotherapy. Pharmacol Therapeut 2008; 117: 354-73.

[23] Paradis ME, Badellino KO, Rader DJ, et al. Visceral adiposity and endothelial lipase. J Clin Endocrinol Metab 2006; 91: 3538-43.

[24] Grundy SM. Atherogenic dyslipidaemia associated with metabolic syndrome and insulin resistance. Clin Cornerstone 2006; 8: S21 S27.

[25] Kohen AR, Basciano H, Adeli K. Lipid and lipoprotein dysregulation in insulin resistant states. Clin Chim Acta 2006; 368: 1-19.

[26] Bugianesi E, Gastaldelli A, Vanni E, et al. Insulin resistance in non-diabetic patients with non-alcoholic fatty liver disease: sites and mechanisms. Diabetologia 2005; 48: 634-42.

[27] Faraj M, Lu HL, Cianflone K. Diabetes, lipids, and adipocyte secretagogues. Biochem Cell Biol 2004; 82: 170-90.

[28] Morton RE. Cholesteryl ester transfer protein and its plasma regulator: lipid transfer inhibitor protein. Curr Opin Lipidol 1999; 10: 321-7.

[29] Arai T, Yamashita S, Hirano K, et al. Increased plasma cholesteryl ester transfer protein in obese subjects: a possible mechanism for the reduction of serum HDL cholesterol levels in obesity. Arterioscler Thromb 1994; 14: 1129-36.

[30] Lewis GF, Uffelman KD, Szeto LW, et al. Interaction between free fatty acids and insulin in the acute control of very low density lipoprotein production in humans. J Clin Invest 1995; 95: 158-66.

[31] Bodary PF, Iglay HB, Eitzman DT. Strategies to reduce vascular risk associated with obesity. Curr Vasc Pharmacol 2007; 5: 24958 .

[32] Athyros VG, Mikhailidis DP, Papageorgiou AA, et al. GREACE Collaborative Group. Effect of atorvastatin on high density lipoprotein cholesterol and its relationship with coronary events: a subgroup analysis of the GREek Atorvastatin and Coronary-heartdisease Evaluation (GREACE) Study. Curr Med Res Opin 2004; 20: 627-37.

[33] Krauss RM. Lipids and lipoproteins in patients with type 2 diabetes. Diabetes Care 2004; 27: 1496-1504.

[34] Taskinen MR. Type 2 diabetes as a lipid disorder. Curr Mol Med 2005; 5: 297-308.

[35] Taskinen MR. Lipoprotein lipase in diabetes. Diabetes Metab Rev 1987; 3: 551-70.

[36] Rashid S, Uffelman KD, Lewis GF. The mechanism of HDL lowering in hypertriglyceridemic, insulin-resistant states. J Diabetes Complicat 2002; 16: 24-8.

[37] Kakafika AI, Liberopoulos EN, Karagiannis A, Athyros VG, Mikhailidis DP. Dyslipidaemia, hypercoagulability and the metabolic syndrome. Curr Vasc Pharmacol 2006; 4: 175-83.

[38] Rashid S, Watanabe T, Sakaue T, Lewis GF. Mechanisms of HDL lowering in insulin resistant, hypertriglyceridemic states: the combined effect of HDL triglyceride enrichment and elevated hepatic lipase activity. Clin Biochem 2003; 36: 421-9.

[39] Wilson PW, Grundy SM. The metabolic syndrome: practical guide to origins and treatment: part I. Circulation 2003; 108: 1422-4.

[40] Lewis GF, Rashid S, Uffelman KD, Lamarche B. Mechanism of HDL lowering in insulin resistant states. Adv Exp Med Biol 2001; 498: 273-7.

[41] Reilly MP, Rader DJ. The metabolic syndrome: more than the sum of its parts? Circulation 2003; 108: 1546-51.

[42] Lagos KG, Filippatos TD, Tsimihodimos V, et al. Alterations in the high density lipoprotein phenotype and HDL-associated enzymes in subjects with metabolic syndrome. Lipids 2009; 44: 9-16.

[43] Tchernof A, Lamarche B, Prud'Homme D, et al. The dense LDL phenotype. Association with plasma lipoprotein levels, visceral 
obesity, and hyperinsulinemia in men. Diabetes Care 1996; 19: 629-37.

[44] Tack CJ, Smits P, Demacker PN, Stalenhoef AF. Troglitazone decreases the proportion of small, dense LDL and increases the resistance of LDL to oxidation in obese subjects. Diabetes Care 1998; 21: 796-9.

[45] Gazi IF, Tsimihodimos V, Tselepis AD, Elisaf M, Mikhailidis DP. Clinical importance and therapeutic modulation of small dense low-density lipoprotein particles. Expert Opin Biol Ther 2007; 7 : 53-72.

[46] Packard CJ. Triacylglycerol-rich lipoproteins and the generation of small, dense low-density lipoprotein. Biochem Soc Trans 2003; 31: 1066-9.

[47] Lamarche B, Tchernof A, Mauriege P, et al. Fasting insulin and apolipoprotein B levels and low-density lipoprotein particle size as risk factors for ischemic heart disease. JAMA 1998; 279: 1955-61.

[48] Chait A, Brazg RL, Tribble DL, et al. Susceptibility of small, dense, low-density lipoproteins to oxidative modification in subjects with the atherogenic lipoprotein phenotype, pattern B. Am J Med 1993; 94: 350-6.

[49] Kwiterovich PO Jr, Coresh J, Smith HH, et al. Comparison of the plasma levels of apolipoproteins B and A-1, and other risk factors in men and women with premature coronary artery disease. Am J Cardiol 1992; 69: 1015-21.

[50] Kwiterovich PO Jr, Coresh J, Bachorik PS. Prevalence of hyperapobetalipoproteinemia and other lipoprotein phenotypes in men (aged $\leq 50$ years) and women ( $\leq 60$ years) with coronary arterydisease. Am J Cardiol 1993; 71: 631-9.

[51] Satoh N, Wada H, Ono K, et al. Small dense LDL-cholesterol relative to LDL-cholesterol is a strong independent determinant of hypoadiponectinemia in metabolic syndrome. Circ J 2008; 72: 9329.

[52] Austin MA, Hokanson JE, Edwards KL. Hypertriglyceridemia as a cardiovascular risk factor. Am J Cardiol 1998; 81: 7B-12B

[53] van Oostrom AJ, Alipour A, Sijmonsma TP, et al. Comparison of different methods to investigate postprandial lipaemia. Neth J Med 2009; 67: 13-20.

[54] Athyros VG, Kakafika AI, Papageorgiou AA, et al; GREACE Study Collaborative Group. Atorvastatin decreases triacylglycerolassociated risk of vascular events in coronary heart disease patients. Lipids 2007; 42: 999-1009.

[55] Kolovou GD, Anagnostopoulou KK, Daskalopoulou SS, Mikhailidis DP, Cokkinos DV. Clinical relevance of postprandial lipaemia. Curr Med Chem 2005; 12: 1931-45.

[56] Davignon J, Cohn JS. Triglycerides: a risk factor for coronary heart disease. Atherosclerosis 1996; 124(suppl): S57-64.

[57] O'Meara NM, Lewis GF, Cabana VG, Iverius PH, Getz GS, Polonsky KS. Role of basal triglyceride and high density lipoprotein in determination of postprandial lipid and lipoprotein responses. J Clin Endocrinol Metab 1992; 75: 465-71.

[58] Weintraub MS, Grosskopf I, Rassin T, et al. Clearance of chylomicron remnants in normolipidaemic patients with coronary artery disease: case control study over three years. BMJ 1996; 312: 936-9.

[59] Karpe F, Steiner G, Uffelman K, Olivecrona T, Hamsten A. Postprandial lipoproteins and progression of coronary atherosclerosis. Atherosclerosis 1994; 106: 83-97.

[60] Ginsberg HN. Efficacy and mechanisms of action of statins in the treatment of diabetic dyslipidemia. J Clin Endocrinol Metab 2006; 91: 383-92.

[61] Ginsberg HN, Illingworth DR. Postprandial dyslipidemia: an atherogenic disorder common in patients with diabetes mellitus. Am J Cardiol 2001; 88 (6A): 9H-15H.

[62] Rebuffe-Scrive M, Lonnroth P, Marin P, et al. Regional adipose tissue metabolism in men and postmenopausal women. Int $\mathrm{J}$ Obes 1987; 11: 347-55.

[63] Lewis GF, Uffelman KD, Szeto LW, Steiner G. Effects of acute hyperinsulinemia on VLDL triglyceride and VLDL apoB production in normal weight and obese individuals. Diabetes 1993; 42: 833-42.

[64] Malmstrom R, Packard CJ, Watson TD, et al. Metabolic basis of hypotriglyceridemic effects of insulin in normal men. Arterioscler Thromb Vasc Biol 1997; 17: 1454-64.

[65] Filippatos TD, Tsimihodimos V, Kostapanos M, et al. Small dense LDL cholesterol and apolipoproteins C-II and C-III in non-diabetic obese subjects with metabolic syndrome. Arch Med Sci 2008; 4: 263-9.
[66] Ezzati M, Hoorn SV, Rodgers A, Lopez AD, Mathers CD, Murray CJL. Comparative Risk Assessment Collaborating Group. Estimates of global and regional potential health gains from reducing multiple major risk factors. Lancet 2003; 362: 271-80.

[67] Liberopoulos EN, Tsouli S, Mikhailidis DP, Elisaf MS. Preventing type 2 diabetes in high risk patients: an overview of lifestyle and pharmacological measures. Curr Drug Targets 2006; 7: 211-28.

[68] Saint-Marc P, Kozak LP, Ailhaud G, Darimont C, Negrel R. Angiotensin II as a trophic factor of white adipose tissue: stimulation of adipose cell formation. Endocrinology 2001; 142: 487-92.

[69] Filippatos TD, Kiortsis DN, Liberopoulos EN, Mikhailidis DP, Elisaf MS. A review of the metabolic effects of sibutramine. Curr Med Res Opin 2005; 21: 457-68.

[70] Valsamakis G, McTernan PG, Chetty R, et al. Modest weight loss and reduction in waist circumference after medical treatment are associated with favorable changes in serum adipocytokines. Metabolism 2004; 53: 430-4.

[71] Didangelos TP, Thanopoulou AK, Bousboulas $\mathrm{SH}$, et al. The ORLIstat and CArdiovascular risk profile in patients with metabolic syndrome and type 2 DIAbetes (ORLICARDIA) Study. Curr Med Res Opin 2004; 20: 1393-1401.

[72] Torgerson JS, Hauptman J, Boldrin MN, Sjostrom L. XENical in the prevention of diabetes in obese subjects (XENDOS) study: a randomized study of orlistat as an adjunct to lifestyle changes for the prevention of type 2 diabetes in obese patients. Diabetes Care 2004; 27: 155-61.

[73] Hanefeld M, Sachse G. The effects of orlistat on body weight and glycaemic control in overweight patients with type 2 diabetes: a randomized, placebo-controlled trial. Diabetes Obes Metab 2002; 4: 415-22.

[74] Kelley DE, Bray GA, Pi-Sunyer FX, et al. Clinical efficacy of orlistat therapy in overweight and obese patients with insulintreated type 2 diabetes. A 1-year randomized controlled trial. Diabetes Care 2002; 25: 1033-41.

[75] Fontaine KR, Redden DT, Wang C, Westfall AO, Allison DB. Years of life lost due to obesity. JAMA 2003; 289: 187-93.

[76] Waseem T, Mogensen KM, Lautz DB, Robinson MK. Pathophysiology of obesity: why surgery remains the most effective treatment. Obes Surg 2007; 17: 1389-98.

[77] Hollenbeak CS, Rogers AM, Barrus B, Wadiwala I, Cooney RN. Surgical volume impacts bariatric surgery mortality: A case for centers of excellence. Surgery 2008; 144: 736-43.

[78] Buchwald H, Avidor Y, Braunwald E, et al. Bariatric surgery: a systematic review and meta-analysis. JAMA 2004; 292: 1724-37.

[79] Pories WJ. Bariatric surgery: risks and rewards. J Clin Endocrinol Metab 2008; 93 (Suppl 1): S89-96.

[80] Swarbrick MM, Stanhope KL, Austrheim-Smith IT, et al. Longitudinal changes in pancreatic and adipocyte hormones following Roux-en-Y gastric bypass surgery. Diabetologia 2008; 51: 190111.

[81] Liou JM, Lin JT, Lee WJ, et al. The serial changes of ghrelin and leptin levels and their relations to weight loss after laparoscopic minigastric bypass surgery. Obes Surg 2008; 18: 84-9.

[82] Whitson BA, Leslie DB, Kellogg TA, et al. Adipokine response in diabetics and nondiabetics following the Roux-en-Y gastric bypass: a preliminary study. J Surg Res 2007; 142: 295-300.

[83] Jialala I, Bajajb M. Therapy and clinical trials: management of diabetic dyslipidemia. Curr Opin Lipidol 2009; 20: 85-6.

[84] Colhoun HM, Betteridge DJ, Durrington PN, et al. Primary prevention of cardiovascular disease with Atorvastatin in type II diabetes in the Collaborative Atorvastatin Diabetes Study (CARDS): multicentre randomised placebocontrolled trial. Lancet 2004; 364: 68596.

[85] Athyros VG, Mikhailidis DP, Liberopoulos EN, et al. Effect of statin treatment on renal function and serum uric acid levels and their relation to vascular events in patients with coronary heart disease and metabolic syndrome: a subgroup analysis of the GREek Atorvastatin and Coronary heart disease Evaluation (GREACE) Study. Nephrol Dial Transplant 2007; 22: 118-27.

[86] Athyros VG, Papageorgiou AA, Symeonidis AN, et al; GREACE Study Collaborative Group. Early benefit from structured care with atorvastatin in patients with coronary heart disease and diabetes mellitus. Angiology 2003; 54: 679-90.

[87] Collins R, Armitage J, Parish S, et al. MRC/BHF heart protection study of cholesterol-lowering with simvastatin in 5963 people with 
diabetes: a randomised placebo-controlled trial. Lancet 2003; 361: 2005-16.

[88] Shepherd J, Barter P, Carmena R, et al. Effect of lowering LDL cholesterol substantially below currently recommended levels in patients with coronary heart disease and diabetes. The Treating to New Targets (TNT) study. Diabetes Care 2006; 29: 1220-6.

[89] Deedwania P, Barter P, Carmena R, et al. Reduction of low-density lipoprotein cholesterol in patients with coronary heart disease and metabolic syndrome: Analysis of the Treating to New Targets study. Lancet 2006; 368: 919-28.

[90] Cholesterol Treatment Trialist' (CTT) Collaborators. Efficacy of cholesterol lowering therapy in 18686 people with diabetes in 14 randomised trails trials of statins. Lancet 2008; 371: 117-25.

[91] Ridker PM, Danielson E, Fonseca FAH, et al. Rosuvastatin to prevent vascular events in men and women with elevated c-reactive protein. N Engl J Med 2008; 359: 2195-2207.

[92] Fruchart JC, Sacks FM, Hermans MP, et al. The Residual Risk Reduction Initiative: a call to action to reduce residual vascular risk in dyslipidaemic patients. A condensed position paper by the Residual Risk Reduction initiative (R3i). Diabetes Vasc Dis Res 2008; 5: 319-35.

[93] Karalis DG. The role of lipid-lowering therapy in preventing coronary heart disease in patients with type 2 diabetes. Clin Cardiol 2008; 31: 241-8.

[94] Sachdeva A, Cannon CP, Deedwania PC, et al; on behalf of the GWTG Steering Committee and Hospitals. Lipid levels in patients hospitalized with coronary artery disease: An analysis of 136, 905 hospitalizations in Get with the Guidelines. Am Heart J 2009; 157: 111-7.

[95] Athyros VG, Mikhailidis DP, Kakafika AI, et al. Identifying and attaining LDL-C goals: mission accomplished? Next target: new therapeutic options to raise HDL-C levels. Curr Drug Targets 2007; 8: 483-8.

[96] Nissen SE, Nicholls SJ, Sipahi I, et al. ASTEROID Investigators. Effect of very high-intensity statin therapy on regression of coronary atherosclerosis: the ASTEROID trial. JAMA 2006; 295: 155665.

[97] Nicholls SJ, Tuzcu EM, Sipahi I, et al. Statins, high-density lipoprotein cholesterol, and regression of coronary atherosclerosis. JAMA 2007; 297: 499-508.

[98] Athyros VG, Kakafika A, Karagiannis A, Mikhailidis DP. Statins and regression of coronary atherosclerosis. JAMA 2007; 297: 2197.

[99] Kostapanos MS, Milionis HJ, Filippatos TD, et al. Dose-dependent effect of rosuvastatin treatment on HDL-subfraction phenotype in patients with primary hyperlipidemia. J Cardiovasc Pharmacol Ther $2009 ; 14: 5-13$.

[100] Ikewaki K, Terao Y, Ozasa H, et al. Effects of atorvastatin on nuclear magnetic resonance-defined lipoprotein subclasses and inflammatory markers in patients with hypercholesterolemia. J Atheroscler Thromb 2009; 16: 51-6.

[101] Kolovou GD, Anagnostopoulou KK, Salpea KD, Daskalopoulou SS, Mikhailidis DP. The effect of statins on postprandial lipemia. Curr Drug Targets 2007; 8: 551-60.

[102] Athyros VG, Kakafika AI, Papageorgiou AA, et al. Statin-induced increase in HDL-C and renal function in coronary heart disease patients. Open Cardiovasc Med J 2007; 1: 8-14.

[103] Athyros VG, Mikhailidis DP, Papageorgiou AA, et al. The effect of statins versus untreated dyslipidaemia on renal function in patients with coronary heart disease. A subgroup analysis of the Greek atorvastatin and coronary heart disease evaluation (GREACE) study. J Clin Pathol 2004; 57: 728-34.

[104] Athyros VG, Papageorgiou AA, Elisaf M, Mikhailidis DP; GREACE Study Collaborative Group. Statins and renal function in patients with diabetes mellitus. Curr Med Res Opin 2003; 19: 6157.

[105] Liberopoulos EN, Mikhailidis DP, Athyros VG, Elisaf MS. The effect of cholesterol-lowering treatment on renal function. Am J Kidney Dis 2006; 47: 561.

[106] Athyros VG, Karagiannis A, Kakafika A, Elisaf M, Mikhailidis DP. Statins and renal function. Is the compound and dose making a difference? Nephrol Dial Transplant 2007; 22: 963-4.

[107] Kakafika A, Athyros VG, Tziomalos K, Karagiannis A, Mikhailidis DP. High density lipoprotein cholesterol and statin trials. Curr Med Chem 2008; 15: 2265-70.

[108] Bloomfield D, Carlson GL, Sapre A, et al. Efficacy and safety of the cholesteryl ester transfer protein inhibitor anacetrapib as mono- therapy and coadministered with atorvastatin in dyslipidemic patients. Am Heart J 2009; 157: 352-60.e2.

[109] Barter PJ, Caulfield M, Eriksson M, et al. For the ILLUMINATE Investigators. Effects of torcetrapib in patients at high risk for coronary events. N Engl J Med 2007; 357: 2109-22.

[110] Forrest MJ, Bloomfield D, Briscoe RJ, et al. Torcetrapib-induced blood pressure elevation is independent of cholesteryl ester transfer protein inhibition and is accompanied by increased circulating levels of aldosterone. Br J Pharmacol 2008; 154: 1465-73.

[111] Brown BG, Xue-Qiao Z, Chait A, et al. Simvastatin and niacin, antioxidant vitamins, or the combination for the prevention of coronary disease. N Engl J Med 2008; 345: 1583-92.

[112] Taylor AJ, Lee HJ, Sullenberger LE. The effect of 24 mo of combination statin and extended-release niacin on carotid intima media thickness: ARBITER 3. Curr Med Res Opin 2006; 22: 2243-50.

[113] Grundy SM, Cleeman JI, Merz CN, et al. National Heart, Lung, and Blood Institute; American College of Cardiology Foundation; American Heart Association. Implications of recent clinical trials for the National Cholesterol Education Program Adult Treatment Panel III guidelines. Circulation 2004; 110: 227-39.

[114] American Diabetes Association: Management of dyslipidemia in adults with diabetes (Position Statement). Diabetes Care 2001; 24 (Suppl. 1): 58-61.

[115] Athyros VG, Kakafika AI, Wierzbicki AS, Karagiannis A, Mikhailidis DP. Targeting triglycerides in secondary prevention: should we bother? Int J Clin Pract 2009; 63: 15-8.

[116] Miller M, Cannon CP, Murphy SA, et al. Impact of triglyceride levels beyond low-density lipoprotein cholesterol after acute coronary syndrome in the PROVE IT-TIMI 22 trial. J Am Coll Cardiol 2008; 51: 724-30.

[117] Tziomalos K, Athyros VG. Fenofibrate: a novel formulation (Triglide) in the treatment of lipid disorders: a review. Int $\mathbf{J}$ Nanomedicine 2006; 1: 129-47.

[118] Frick MH, Elo O, Haapa K, et al. Helsinki Heart Study: primary prevention trial with gemfibrozil in middle-aged men with dyslipidemia. Safety of treatment, changes in risk factors, and incidence of coronary heart disease. N Engl J Med 1987; 317: 1237-45.

[119] Rubins HB, Robins SJ, Collins D, et al. Gemfibrozil for the secondary prevention of coronary heart disease in men with low levels of highdensity lipoprotein cholesterol. Veterans Affairs High-Density Lipoprotein Cholesterol Intervention Trial Study Group. N Engl J Med 1999; 341: 410-8.

[120] The Bezafibrate Infarction Prevention (BIP) study group. Secondary prevention by raising HDL cholesterol and reducing triglycerides in patients with coronary artery disease. The Bezafibrate Infarction Prevention (BIP) study. Circulation 2000; 102: 21-7.

[121] Keech A, Simes RJ, Barter P, et al. The FIELD study investigators. Effects of long-term fenofibrate therapy on cardiovascular events in 9795 people with type 2 diabetes mellitus (the FIELD study): randomised controlled trial. Lancet 2005; 366: 1849-61.

[122] Pourcet B, Fruchart JC, Staels B, Glineur C. Selective PPAR modulators, dual and pan PPAR agonists: multimodal drugs for the treatment of type 2 diabetes and atherosclerosis. Expert Opin Emerg Drugs 2006; 11: 379-401.

[123] Gross B, Staels B. PPAR agonists: multimodal drugs for the treatment of type- 2 diabetes. Best Pract Res Clin Endocrinol Metab 2007; 21: 687-710.

[124] Staels B, Fruchart JC. Therapeutic roles of peroxisome proliferator activated receptor agonists. Diabetes 2005; 54: 2460-70.

[125] Ooi TC, Cousins M, Ooi DS, Nakajima K, Edwards AL. Effect of fibrates on postprandial remnant-like particles in patients with combined hyperlipidemia. Atherosclerosis 2004; 172: 375-82.

[126] Rosenson RS, Wolff DA, Huskin AL, Helenowski IB, Rademaker RW. Fenofibrate therapy ameliorates fasting and postprandial lipoproteinemia, oxidative stress, and the inflammatory response in subjects with hypertriglyceridemia and the metabolic syndrome. Diabetes Care 2007; 30: 1945-51.

[127] Duez H, Lefebvre B, Poulain P, et al. Regulation of human apo A-I by gemfibrozil and fenofibrate through selective peroxisome proliferator activated receptor alpha modulation. Arterioscler Thromb Vasc Biol 2005; 25: 585-91.

[128] Chapman MJ. Fibrates in 2003: therapeutic action in atherogenic dyslipidaemia and future perspectives. Atherosclerosis 2003; 171: $1-13$.

[129] Ikewaki K, Tohyama J, Nakata Y, Wakikawa T, Kido T, Mochizuki S. Fenofibrate effectively reduces remnants, and small dense 
LDL, and increases HDL particle number in hypertriglyceridemic men - a nuclear magnetic resonance study. J Atheroscler Thromb 2004; 11: 278-85.

[130] Ooi TC, Heinonen T, Alaupovic P, et al. Efficacy and safety of a new hydroxymethylglutaryl-coenzyme A reductase inhibitor, atorvastatin, in patients with combined hyperlipidemia: comparison with fenofibrate. Arterioscler Thromb Vasc Biol 1997; 17: 1793-9.

[131] Wagner JA, Larson PJ, Weiss S, et al. Individual and combined effects of peroxisome proliferator-activated receptor and gamma agonists, fenofibrate and rosiglitazone, on biomarkers of lipid and glucose metabolism in healthy nondiabetic volunteers. J Clin Pharmacol 2005; 45: 504-13.

[132] Davidson MH, Bays HE, Stein E, Maki KC, Shalwitz RA, Doyle $\mathrm{R}$, TRIMS Investigators. Effects of fenofibrate on atherogenic dyslipidemia in hypertriglyceridemic subjects. Clin Cardiol 2006; 29: 268-73.

[133] Tsimihodimos V, Kostoula A, Kakafika A, et al. Effect of fenofibrate on serum inflammatory markers in patients with high triglyceride values. J Cardiovasc Pharmacol Ther 2004; 9: 27-33.

[134] The FIELD study investigators. Effect of long-term fenofibrate therapy on cardiovascular events in 9795 people with type 2 diabetes mellitus (the FIELD study): randomised controlled trial. Lancet 2005; 366: 1849-61.

[135] Steinmertz A. Lipid-lowering therapy in patients with type 2 diabetes: the case for early intervention. Diabetes Metab Res Rev 2008; 24: 286-93.

[136] Athyros V, Papageorgiou A, Hagikonstantinou H, Papadopoulos G, Zamboulis C, Kontopoulos A. Combined treatment with pravastatin and gemfibrozil in patients with refractory familial combined hyperlipidaemia. Drug Invest 1994; 7: 134-42.

[137] Athyros VG, Papageorgiou AA, Hatzikonstandinou HA, et al. Safety and efficacy of long-term statin-fibrate combinations in patients with refractory familial combined hyperlipidemia. Am J Cardiol 1997; 80: 608-13.

[138] Athyros VG, Papageorgiou AA, Athyrou VV, Demitriadis DS, Pehlivanidis AN, Kontopoulos AG. Atorvastatin versus four statinfibrate combinations in patients with familial combined hyperlipidaemia. J Cardiovasc Risk 2002; 9: 33-9.

[139] Kontopoulos AG, Athyros VG, Papageorgiou AA, Hatzikonstandinou HA, Mayroudi MC, Boudoulas H. Effects of simvastatin and ciprofibrate alone and in combination on lipid profile, plasma fibrinogen and low density lipoprotein particle structure and distribution in patients with familial combined hyperlipidaemia and coronary artery disease. Coron Artery Dis 1996; 7: 843-50.

[140] Pierce LR, Wysowski DK, Gross TP. Myopathy and rhabdomyolysis associated with lovastatin-gemfibrozil combination therapy. JAMA 1990; 264: 71-5.

[141] Wierzbicki AS, Mikhailidis DP, Wray R, et al. Statin-fibrate combination: therapy for hyperlipidemia: a review. Curr Med Res Opin 2003; 19: 155-68.

[142] Jones PH, Davidson MH, Kashyap ML, et al. Efficacy and safety of ABT-335 (fenofibric acid) in combination with rosuvastatin in patients with mixed dyslipidemia: A phase 3 study. Atherosclerosis 2009; 204(1): 208-5.

[143] Athyros VG, Papageorgiou AA, Kontopoulos AG. Statin-fibrate combinations in patients with combined hyperlipedemia. Atherosclerosis 2001; 155: 263-4.

[144] Farnier M, Picard S. Diabetes: statins, fibrates, or both? Curr Atheroscler Rep 2001; 3: 19-28.

[145] Bucala R, Makita Z, Vega G, et al. Modification of low density lipoprotein by advanced glycation end products contributes to the dyslipidemia of diabetes and renal insufficiency. Proc Natl Acad Sci USA 1994; 91: 9441-5.

[146] Stern MP, Mitchell BD, Haffner SM, Hazuda HP. Does glycemic control of type-2 diabetes suffice to control diabetic dyslipidemia? A community perspective. Diabetes Care 1992; 15: 638-44.

[147] Filippatos TD, Gazi IF, Liberopoulos EN, et al. The effect of orlistat and fenofibrate, alone or in combination, on small dense LDL and lipoprotein-associated phospholipase A2 in obese patients with metabolic syndrome. Atherosclerosis 2007; 193: 428-37.

[148] Athyros VG, Papageorgiou AA, Athyrou VV, Demitriadis DS, Kontopoulos AG. Atorvastatin and micronized fenofibrate alone and in combination in type 2 diabetes with combined hyperlipidemia. Diabetes Care 2002; 25: 1198-202.

[149] Athyros VG, Kakafika AI, Karagiannis A, Mikhailidis DP. Effects of simvastatin alone versus fenofibrate alone versus simvastatin plus fenofibrate on lipoprotein subparticle profiles in patients with diabetes mellitus and mixed dyslipidemia. Am J Cardiol 2008; 101: 1679-80.

[150] Mulhall BP, Ong JP, Younossi ZM. Non-alcoholic fatty liver disease: An overview. J Gastroenterol Hepatol 2002; 17: 1136-42.

[151] Marchesini G, Brizi M, Morselli Labate AM, et al. Association of non-alcoholic fatty liver disease to insulin resistance. Am J Med 1999; 107: 450-5.

[152] Expert Panel on Detection, Evaluation, and Treatment of High Blood Cholesterol in Adults. Executive Summary of the Third Report of the National Cholesterol Education Program (NCEP) Expert Panel on Detection, Evaluation, and Treatment of High Blood Cholesterol in Adults (Adult Treatment Panel III). JAMA 2001; 285: 2486-97.

[153] DeFronzo RA, Ferrannini E. Insulin resistance: a multifaceted syndrome responsible for NIDDM, obesity, hypertension, dyslipidemia, and atherosclerotic cardiovascular disease. Diabetes Care 1991; 14: 173-94.

[154] Cortez-Pinto H, Camilo ME, Baptista A, De Oliveira AG, De Moura MC. Non-alcoholic fatty liver: another feature of the metabolic syndrome? Clin Nutr 1999; 18: 353-8.

[155] Adams LA, Lindor KD. Treatment of hyperlipidemia in nonalcoholic fatty liver disease: Fat for thought. Indian $\mathrm{J}$ Gastroenterol 2004; 23: 127-8.

[156] Athyros VG, Kakafika AI, Karagiannis A, Mikhailidis DP. Do we need to consider inflammatory markers when we treat atherosclerotic disease? Atherosclerosis 2008; 200: 1-12.

[157] Athyros VG, Mikhailidis DP, Papageorgiou AA, et al. Targeting vascular risk in patients with metabolic syndrome but without diabetes. Metabolism 2005; 54: 1065-74.

[158] Athyros VG, Mikhailidis DP, Didangelos TP, et al. Effect of multifactorial treatment on non-alcoholic fatty liver disease in metabolic syndrome: a randomised study. Curr Med Res Opin 2006; 22: 87383.

[159] Harris WS, Connor WE, Alam N, Illingworth DR. Reduction of postprandial triglyceridemia in humans by dietary $\mathrm{n}-3$ fatty acids. J Lipid Res 1988; 29: 1451-60.

[160] Montori VM, Farmer A, Wollan PC, Dinheen SF. Fish oil supplementation in type 2 diabetes: a quantitative systemic review. Diabetes Care 2000; 23: 1407-15.

[161] Tziomalos K, Athyros VG, Mikhailidis DP. Fish oils and vascular disease prevention: an update. Curr Med Chem 2007; 14: 2622-8.

[162] Yokoyama M, Origasa H, Matsuzaki M, et al. Japan EPA Lipid Intervention Study (JELIS) Investigators. Effects of eicosapentaenoic acid on major coronary events in hypercholesterolaemic patients (JELIS): a randomised open-label, blinded endpoint analysis. Lancet 2007; 369: 1090-8.

[163] Saito Y, Yokoyama M, Origasa H, et al. JELIS Investigators, Japan. Effects of EPA on coronary artery disease in hypercholesterolemic patients with multiple risk factors: sub-analysis of primary prevention cases from the Japan EPA Lipid Intervention Study (JELIS). Atherosclerosis 2008; 200: 135-140.

[164] Daviglus ML, Stamler J, Orencia AJ, et al. Fish consumption and the 30-year risk of fatal myocardial infarction. N Engl J Med 1997; 336: 1046-53.

[165] Kromhout D, Bosschieter EB, de Lezenne CC. The inverse relation between fish consumption and 20-year mortality from coronary heart disease. N Engl J Med 1985; 312: 1205-9.

[166] Albert CM, Hennekens CH, O'Donnell CJ, et al. Fish consumption and risk of sudden cardiac death. JAMA 1998; 279: 23-8.

[167] Iso H, Kobayashi M, Ishihara J, et al. For the JPHC Study Group. Intake of fish and $\mathrm{n} 3$ fatty acids and risk of coronary heart disease among Japanese. The Japan Public Health Center-Based (JPHC) Study Cohort I. Circulation 2006; 113: 195-202.

[168] Mita T, Watada H, Ogihara T, et al. Eicosapentaenoic acid reduces the progression of carotid intima-media thickness in patients with type 2 diabetes. Atherosclerosis 2007; 191: 162-7.

[169] Leaf A. Omega-3 fatty acids and prevention of arrhythmias. Curr Opin Lipidol 2007; 18: 31-4.

[170] Mozaffarian D. JELIS, fish oil, and cardiac events. Lancet 2007; 369: 1062-3

[171] Nambi V, Ballantyne CM. Combination therapy with statins and omega-3 fatty acids. Am J Cardiol 2006; 98 (Suppl 4A): 34i8 i.

[172] Smith SC Jr, Allen J, Blair SN, et al; AHA/ACC; National Heart, Lung, and Blood Institute. AHA/ACC guidelines for secondary 
prevention for patients with coronary and other atherosclerotic vascular disease: 2006 update: endorsed by the National Heart, Lung, and Blood Institute. Circulation 2006; 113: 2363-72.

[173] Pearson TA, Ballantyne CM, Veltri E, et al. Pooled analyses of effects on C-reactive protein and low density lipoprotein cholesterol in placebo-controlled trials of ezetimibe monotherapy or ezetimibe added to baseline statin therapy. Am J Cardiol 2009; 103: 369-74

[174] Mikhailidis DP, Sibbring GC, Ballantyne CM, Davies GM, Catapano AL. Meta-analysis of the cholesterol-lowering effect of ezetimibe added to ongoing statin therapy. Curr Med Res Opin 2007; 23: 2009-26.

[175] Nakou ES, Filippatos TD, Georgoula M, et al. The effect of orlistat and ezetimibe, alone or in combination, on serum LDL and small dense LDL cholesterol levels in overweight and obese patients with hypercholesterolaemia. Curr Med Res Opin 2008; 24: 1919-29.

[176] Kalogirou M, Tsimihodimos V, Gazi I, et al. Effect of ezetimibe monotherapy on the concentration of lipoprotein subfractions in patients with primary dyslipidaemia. Curr Med Res Opin 2007; 23 : 1169-76.

[177] Gazi IF, Mikhailidis DP. Non-low-density lipoprotein cholesterolassociated actions of ezetimibe: an overview. Expert Opin Ther Targets 2006; 10: 851-66.

[178] Fras Z, Mikhailidis DP. Statin plus ezetimibe treatment in clinical practice: the SI-SPECT (Slovenia (SI) Statin Plus Ezetimibe in Cholesterol Treatment) monitoring of clinical practice study. Curr Med Res Opin 2008; 24: 2467-76.

[179] Athyros VG, Tziomalos K, Kakafika AI, Koumaras H, Karagiannis A, Mikhailidis DP. Effectiveness of ezetimibe alone or in combination with twice a week Atorvastatin $(10 \mathrm{mg})$ for statin intolerant high-risk patients. Am J Cardiol 2008; 101: 483-5.

[180] Gazi IF, Daskalopoulou SS, Nair DR, Mikhailidis DP. Effect of ezetimibe in patients who cannot tolerate statins or cannot get to the low density lipoprotein cholesterol target despite taking a statin. Curr Med Res Opin 2007; 23: 2183-92.

[181] Goldberg RB, Guyton JR, Mazzone T, et al. Ezetimibe/simvastatin vs atorvastatin in patients with type 2 diabetes mellitus and hypercholesterolemia: the VYTAL study. Mayo Clin Proc 2006; 81: $1579-88$

[182] Denke M, Pearson T, McBride P, Gazzara RA, Brady WE, Tershakovec AM. Ezetimibe added to ongoing statin therapy improves LDL-C goal attainment and lipid profile in patients with diabetes or metabolic syndrome. Diab Vasc Dis Res 2006; 3: 93-102.

[183] Hajer GR, Dallinga-Thie GM, van Vark-van der Zee LC, Visseren FL. The effect of statin alone or in combination with ezetimibe on postprandial lipoprotein composition in obese metabolic syndrome patients. Atherosclerosis 2009; 202: 216-24.
[184] Olijhoek JK, Hajer GR, van der Graaf Y, Dallinga-Thie GM, Visseren FL. The effects of low-dose simvastatin and ezetimibe compared to high-dose simvastatin alone on post-fat load endothelial function in patients with metabolic syndrome: a randomized double-blind crossover trial. J Cardiovasc Pharmacol 2008; 52: 145-50.

[185] Barylski M, Kowalczyk E, Banach M, Ciecwierz J, Pawlicki L, Kowalski J. Plasma total antioxidant activity in comparison with plasma NO and VEGF levels in patients with metabolic syndrome. Angiology 2009; 60: 87-92.

[186] Saougos VG, Tambaki AP, Kalogirou M, et al. Differential effect of hypolipidemic drugs on lipoprotein-associated phospholipase A2. Arterioscler Thromb Vasc Biol 2007; 27: 2236-43.

[187] Tribble DL, Farnier M, Macdonell G, et al. Effects of fenofibrate and ezetimibe, both as monotherapy and in coadministration, on cholesterol mass within lipoprotein subfractions and low-density lipoprotein peak particle size in patients with mixed hyperlipidemia. Metabolism 2008; 57: 796-801.

[188] Farnier M, Freeman MW, Macdonell G, et al. The Ezetimibe Study Group. Efficacy and safety of the coadministration of ezetimibe with fenofibrate in patients with mixed hyperlipidaemia. Eur Heart J 2005; 26: 897-905.

[189] Bunzell JD, Davidson M, Furberg CD, et al. Lipoprotein management in patients with cardiometabolic risk. J Am Coll Cardiol 2008; 51: 1512-24.

[190] Kanjilal S, Shanker J, Rao VS, Mukherjee M, Iyengar SS, Kakkar VV. Association of metabolic syndrome with atherothrombotic blood phenotypes in Asian Indian families with premature coronary artery disease. Arch Med Sci 2008; 4: 145-51.

[191] Rizzo M, Berneis K. The clinical significance of the size of lowdensity-lipoproteins and the modulation of subclasses by fibrates Curr Med Res Opin 2007; 23: 1103-11.

[192] Rizzo M, Berneis K, Spinas GA, Rini GB, Kapur NK. Quantitative and qualitative effects of rosuvastatin on LDL-cholesterol: what is the clinical significance? Int J Clin Pract 2009; 63: 478-85.

[193] Tan KC. Reverse cholesterol transport in type 2 diabetes mellitus. Diabetes Obes Metab 2009; 11: 534-43.

[194] Borggreve SE, De Vries R, Dullaart RP. Alterations in high-density lipoprotein metabolism and reverse cholesterol transport in insulin resistance and type 2 diabetes mellitus: role of lipolytic enzymes, lecithin:cholesterol acyltransferase and lipid transfer proteins. Eur J Clin Invest 2003; 33: 1051-69.

[195] Lewis GF, Rader DJ. New insights into the regulation of HDL metabolism and reverse cholesterol transport. Circ Res 2005; 96 : 1221-32 